\title{
A National Study on Gambling Among US College Student-Athletes
}

\author{
Jiun-Hau Huang, SM, ScD; Durand F. Jacobs, PhD; Jeffrey L. Derevensky, PhD; \\ Rina Gupta, PhD; Thomas S. Paskus, PhD
}

\begin{abstract}
Objective: The authors examined the national prevalence of gambling problems and sports wagering among US college student-athletes. Participants: A national sample of 20,739 student-athletes participated in the study. Methods: The authors used data from the first national survey of gambling among college athletes, conducted by the National Collegiate Athletic Association. Results: Men (62.4\%) consistently had higher past-year prevalence of gambling than did women $(42.8 \%)$. The authors identified $4.3 \%$ of men and $0.4 \%$ of women as problem or pathological gamblers. Among the most popular forms of gambling were playing cards, lotteries, and games of skill, with male-tofemale prevalence ratio ranging 1.3-5.6 across various gambling activities. Athletes in golf and lacrosse were more likely to report sports wagering than were other athletes. Athletes in gender-specific sports wagered more prevalently than did athletes in unisex sports. Conclusion: Gambling prevalence may be underestimated in this population because respondents' athletics eligibility is at stake. This study provides important baseline data for future cohorts of athletes.
\end{abstract}

Keywords: college student-athletes, gambling, gender, pathological gambling, prevalence, problem gambling, sports wagering

Y outh gambling has increasingly become a significant public health issue, especially in the wake of the widespread expansion of legalized gambling throughout North America. However, despite considerable consensus in the current literature that youths represent the highest risk group for gambling problems, most researchers have targeted adult gamblers in their studies, and relatively few investigators have focused on or included young adult gamblers in their studies. ${ }^{1-6}$ Researchers ${ }^{7,8}$ echo concerns that youth gambling

Drs Huang, Derevensky, and Gupta are with McGill University's Educational \& Counselling Psychology Department and International Centre for Youth Gambling Problems \& High-Risk Behaviors, Quebec, Canada. Dr Jacobs is with the Department of Psychiatry at Loma Linda University, California. Dr Paskus is with the US National Collegiate Athletic Association.

Copyright $\odot 2007$ Heldref Publications behavior has been understudied and that increased efforts are needed to respond to this growing problem.

From existing prevalence studies over the past 25 years in the United States and Canada, Shaffer and Hall ${ }^{5}$ employed a meta-analytic strategy to synthesize the prevalence estimates of disordered gambling in different population segments. They consistently reported that adolescents and college students were at significantly increased risk for gambling-related problems. For example, they reported that the lifetime prevalence estimates of level 2 (subclinical/ problem) and level 3 (pathological) gambling among adolescents were $8.4 \%$ and $3.4 \%$, respectively, which nearly doubled the estimates for adults $(4.2 \%$ and $1.9 \%$, respectively). Prevalence estimates for college students $(10.9 \%$ and $5.6 \%$, respectively) were even higher than those of adolescents. Although college students are a high-risk group, they have received the least amount of research attention, as evidenced by Shaffer and Hall's ${ }^{5}$ synthesis of gambling research (eg, out of the 139 study samples identified, 19 were from college students, compared with 32 adolescent and 66 adult population studies).

As sparse as the existing literature on college student gambling is, investigators ${ }^{9-11}$ have repeatedly found that problem and pathological gambling among college students is associated with men, alcohol abuse, illicit drug use, risky sexual behavior, and other risk-taking problem behaviors. Engwall et al ${ }^{12}$ recently found, in a small sample of college students, significantly greater problem-gambling rates in athletes than in nonathletes. In particular, the lifetime prevalence of problem and pathological gambling among male student-athletes was $26 \%$, compared with $16 \%$ among male nonathletes. They found the same pattern among women, with female athletes $(7 \%)$ exceeding nonathletes $(4 \%)$ in the prevalence of gambling problems. It should be noted that these estimates were derived from a relatively small sample of students (207 athletes and 1,076 nonathletes) attending a state university "in a progambling culture."12(p 246) 
There have been other prior attempts at quantifying gambling and wagering behavior among select groups of student-athletes. For example, the National Collegiate Athletic Association (NCAA) conducted a self-report study on infractions and found that $25.5 \%$ of Division I men's football and basketball players indicated that they had gambled money on other collegiate sporting events and that $3.7 \%$ had wagered on a game in which they had played. ${ }^{13}$ Cross and Vollano ${ }^{14}$ reported that more than $45 \%$ of Division I men's basketball and football student-athletes gambled on sports while attending college. The researchers in both studies also found that a small number of student-athletes (less than 5\%) reported having provided inside information to gamblers or actually accepting money for playing poorly in a game. ${ }^{13,14}$ However, these prior studies of gambling behavior among NCAA student-athletes employed fairly small samples (less than 1,000) and focused on limited numbers of institutions within Division I high-profile sports only (ie, football and basketball).

To bridge this gap in the literature, we need to assess student-athlete gambling behavior across a broader spectrum of the student-athlete population on a national level. To our knowledge, our study represents the first effort to collect information on gambling and associated behaviors from a national sample of student-athletes. It was groundbreaking in terms of scope and breadth (eg, data were collected from students in all NCAA divisions and from most championship sports).

Our primary goal was to determine the nature and extent of gambling and wagering behaviors among student-athletes at US colleges and universities. Leading into this research effort, college administrations and athletics departments of NCAA member institutions expressed interest in both aggregate findings and group-specific results (eg, by sport). The male and female difference in the prevalence estimates of gambling was also important. Therefore, we estimated the prevalence of sports wagering, accounting for both sport and gender. Further, we analyzed the types of gambling behavior engaged in by male versus female student-athletes. Most of all, with the inclusion of the 10 Diagnostic and Statistical Manual of Mental Disorders, 4th edition $(D S M-I V)^{15}$ Gambling Screen questions, we were able to estimate the national prevalence of problem and pathological gambling among student-athletes. Last, to inform future intervention programs, the main reasons for student-athlete gambling were also quantitatively summarized.

\section{METHODS}

Our study was based on survey data from the 2003 NCAA National Study on Collegiate Sports Wagering and Associated Health-Risk Behaviors. ${ }^{16}$ This self-administered, voluntary, and anonymous survey included 102 questions and is the most comprehensive and first truly national assessment of gambling behavior among US college studentathletes ever undertaken.

\section{Sampling}

We designed the sampling plan so that at least $12 \%$ of the NCAA member institutions that sponsor a given sport would be asked to survey their student-athletes in that sport. We targeted student-athletes in most NCAA championship sports for participation. After devising the sampling plan, we implemented a computer program that sampled institutions at random and selected 1 to 3 sports at each NCAA member institution for study. To minimize institutional burden, we did not ask any school to collect responses from more than 3 of its athletics teams. We ultimately asked students from 2,003 individual sport teams at 1,032 member institutions to participate in the study.

\section{Survey Administration}

The institutional review board at NCAA approved the protocol for this study, and we conducted the survey in consultation with the Directors of Athletics at participating schools. After identifying institutions and selecting sports for those schools, we contacted the Faculty Athletics Representative (FAR) at each NCAA member institution to help conduct the survey. We gave the FAR a specific protocol to follow and a script to read that emphasized that the study was completely voluntary, that each student's responses were anonymous, and that voluntary completion of this study constituted the informed consent to participate, as reiterated on the survey form. The FAR distributed the survey to all adult student-athletes of a sampled team on the same occasion. The last member to complete the survey sealed and sent the preaddressed, prepaid envelope into which student-athletes deposited completed surveys to the NCAA.

\section{Participants}

We received 20,739 valid, individual surveys. Men (approximately 62\%) were slightly overrepresented in the sample responses, compared with the full NCAA studentathlete population ( $58 \%$ men and $42 \%$ women). Among student-athletes reporting their race/ethnicity, $75 \%$ described themselves as white, $15 \%$ as black, and $10 \%$ as from another racial/ethnic group. These proportions approximate those in the overall population of student-athletes.

\section{Analysis}

We cleaned the survey data via a series of validity checks. In addition, we examined responses that indicated unethical behavior (eg, taking money for playing poorly) on a caseby-case basis to determine whether the overall response patterns of those individuals indicated a sincere response to the survey. We removed cases only if we noted completely implausible or extremely conflicting patterns of response. Therefore, we omitted 194 cases and retained 20,739 as valid. We used SPSS (SPSS Inc, Chicago, IL) to perform all descriptive data analyses in the study.

To counteract the effect of underrepresentation of some sports and Division affiliation within the current sample, we used a series of weighting functions as necessary to produce aggregate data that would better and more accurately reflect behavior within the overall student-athlete population or a particular subgroup. Also, we estimated the prevalence of sports wagering and gambling among men and women separately to 
account for differences by gender. We used chi-square tests in some male and female comparisons where appropriate.

The DSM-IV, published by the American Psychiatric Association, provides a list of 10 characteristics of a pathological gambler. We included questions corresponding with the 10 diagnostic criteria in this survey (see Appendix). We summed responses to the 10 items to create a DSM Gambling Screen score, ranging from 0 to 10 . A higher score indicated having more gambling problems. We classified those respondents who reported participation in at least 1 of the 14 gambling activities surveyed in the questionnaire as social gamblers, problem gamblers, and pathological gamblers if they had a $D S M$ score of 0-2, 3-4, and 5 or more, respectively.

We classified those respondents who indicated no participation in any of the 14 gambling activities and who had either a missing DSM score or a score of zero as nongamblers. Note that we instructed respondents who did not engage in any gambling activities during the past 12 months to skip the DSM Gambling Screen questions, and thus, they were missing on the DSM score variable.

We omitted respondents who reported no gambling involvement but who had a DSM score of 1 or more, as well as those who participated in at least 1 of the 14 gambling activities but who had a missing DSM score, from all analyses based on the DSM score. We retained them, however, for all other analyses.

\section{RESULTS}

The past-year prevalence of gambling and sports wagering was consistently higher among male student-athletes than it was among their female counterparts. In our sample of 20,739 student-athletes, more than 3 in 5 men $(62.4 \%$ or $7,987)$ and 2 in 5 women $(42.8 \%$ or 3,313$)$ indicated participation in some type of gambling activity during the past 12 months. Almost $35 \%$ of men $(4,427)$ reported wagering on any sporting events (professional or collegiate) in the past year, compared with nearly $10 \%$ of women (742).

Among male student-athletes, we found the highest prevalence of wagering on any sporting events in golf (48.6\%), ice hockey $(48.4 \%)$, lacrosse $(44.4 \%)$, wrestling (42.0\%), and baseball (39.1\%). In comparison, among female studentathletes, we found the highest prevalence of such wagering among athletes in golf $(16.0 \%)$, lacrosse $(14.2 \%)$, basketball (12.8\%), softball (11.6\%), and soccer (11.0\%; see Table 1).

In regard to the types of gambling behavior engaged in by student-athletes during the past 12 months, among the most prevalent activities were: "Played cards or board games for money (with family or friends)" (35.2\%); "Bought lottery tickets" (33.0\%); "Bet on games of personal skill (like pool, golf, or bowling)" (28.6\%); "Engaged in some other type of gambling" (17.9\%); and "Played slot or electronic poker machines" (16.9\%). We derived these prevalence figures from the entire student-athlete sample, with men and women combined. When examined separately, men had much higher prevalence of participation than did women across all gambling activities, ranging from approximately 1.3 to 5.6 times higher, except for playing commercial bingo (6.4\% men vs
TABLE 1. Past-Year Prevalence and Estimated Numbers of Student-Athletes Who Reported Wagering on Any Sporting Events, by Sport and Gender

\begin{tabular}{|c|c|c|c|c|}
\hline \multirow[b]{2}{*}{ Sport } & \multicolumn{2}{|c|}{ Men } & \multicolumn{2}{|c|}{ Women } \\
\hline & $\%$ & Est. $n$ & $\%$ & Est. $n$ \\
\hline Golf & 48.6 & 3,700 & 16.0 & 600 \\
\hline Ice hockey & 48.4 & 1,800 & - & - \\
\hline Lacrosse & 44.4 & 2,900 & 14.2 & 800 \\
\hline Wrestling & 42.0 & 2,500 & - & - \\
\hline Baseball & 39.1 & 10,300 & - & - \\
\hline Football & 36.0 & 20,900 & - & - \\
\hline Soccer & 35.3 & 6,600 & 11.0 & 2,100 \\
\hline Tennis & 33.0 & 2,500 & 8.3 & 700 \\
\hline Basketball & 32.8 & 5,200 & 12.8 & 1,900 \\
\hline Swimming & 31.0 & 2,300 & 8.1 & 800 \\
\hline Cross country & 27.9 & 3,000 & 5.9 & 700 \\
\hline Outdoor track & 25.2 & 5,100 & 7.2 & 1,300 \\
\hline Softball & - & - & 11.6 & 1,800 \\
\hline Field hockey & - & - & 10.8 & 600 \\
\hline Volleyball & - & - & 9.4 & 1,200 \\
\hline Overall & 34.6 & 66,800 & 9.6 & 12,500 \\
\hline
\end{tabular}

Note. The table is sorted by male prevalence. Dashes indicate that no information existed on such athletes. Est. $n=$ estimated numbers based on numbers of NCAA student-athletes participating in 2001-02 academic year.

$7.4 \%$ women). All chi-square comparisons by gender were statistically significant at $p<.05$. Other highly prevalent gambling activities included "bet on sports cards, football pools or parlays" among men (21.1\%) and "played table games at a casino" among women (7.6\%; see Table 2).

On the basis of the DSM-IV Gambling Screen methodology, we classified $1.2 \%$ (130) and 3.1\% (337) of men as pathological and problem gamblers, respectively. In contrast, we classified $0.1 \%$ (4) and $0.3 \%$ (16) of women as such (see Table $3)$. The chi-square comparison by gender was significant $(p<$ $.05)$. Note that we based our estimates of gambling prevalence on a 12-month time frame, rather than lifetime prevalence.

For both male and female student-athletes, the top 3 reported reasons for student-athlete gambling were "for fun" (75.6\%), "to win money" (53.0\%), and "for excitement" (52.1\%).

Last, we also found that $0.7 \%$ of male (77) and $0.1 \%$ of female (7) student-athletes reported ever accepting money or other reward for playing poorly in a game (see Table 4). Further, "because of a sports wagering debt," $1.1 \%$ of male (115) and $0.6 \%$ of female (34) student-athletes reported ever being asked to affect the outcome of a game in which they played, and $0.5 \%$ of male (55) and $0.2 \%$ of female (9) players reported actually affecting the outcome.

\section{COMMENT}

\section{Gender-Related Differences}

To our knowledge, this study is the first of its kind in which researchers collected national data on gambling and sports 
TABLE 2. Past-Year Prevalence of Gambling Activities Engaged in by Student-Athletes, by Gender

\begin{tabular}{lccc}
\hline \hline Gambling activity & $\begin{array}{c}\text { Men } \\
(n=12,795)\end{array}$ & $\begin{array}{c}\text { Women } \\
(n=7,734)\end{array}$ & $\begin{array}{c}\text { Overall } \\
(N=20,529)\end{array}$ \\
\hline Played cards or board games for money & 45.3 & 18.9 & 35.2 \\
Bought lottery tickets & 35.7 & 28.5 & 33.0 \\
Bet on games of personal skill & 38.0 & 13.3 & 28.6 \\
Engaged in some other type of gambling & 24.4 & 7.4 & 17.9 \\
Played slot or electronic poker machines & 19.2 & 13.0 & 16.9 \\
Bet on sports cards, football pools, or parlays & 21.1 & 5.6 & 15.2 \\
Played table games at a casino & 18.5 & 7.6 & 14.3 \\
Shot dice or played craps & 13.0 & 3.4 & 9.3 \\
Played the stock market & 10.1 & 3.4 & 7.6 \\
Bet on horse or dog races & 9.5 & 4.6 & 7.6 \\
Played commercial bingo & 6.4 & 7.4 & 6.7 \\
Wagered on the Internet on casino or other games & 6.4 & 2.1 & 4.7 \\
Wagered on intercollegiate games with an & & & 2.7 \\
$\quad$ off-campus bookie & 3.9 & 0.7 & 2.7 \\
Wagered on intercollegiate games with a campus & & & 1.8 \\
bookie & 2.7 & 0.5 & \\
\hline
\end{tabular}

Note. The table is sorted by overall prevalence, and all numbers are percentages. The sample size of each gambling activity varied because of missing items and 210 respondents not indicating their gender. Chisquare comparisons were all significant at $p<.05$.

TABLE 3. Past-Year Prevalence of Various Gambling Types on the Basis of DSM-IV Among Student-Athletes, by Gender

\begin{tabular}{lccc}
\hline \hline Gambling type & $\begin{array}{c}\text { Men } \\
(n=10,800)\end{array}$ & $\begin{array}{c}\text { Women } \\
(n=6,276)\end{array}$ & $\begin{array}{c}\text { Overall } \\
(N=17,076)\end{array}$ \\
\hline Nongambling & 43.1 & 70.0 & 53.0 \\
Social gambling & 52.6 & 29.6 & 44.1 \\
Problem gambling & 3.1 & 0.3 & 2.1 \\
Pathological gambling & 1.2 & 0.1 & 0.8 \\
\hline
\end{tabular}

Note. DSM-IV = Diagnostic and Statistical Manual of Mental Disorders, 4 th ed. ${ }^{15}$ The authors excluded 3,663 respondents from this analysis mostly because of missing information on the DSM-IV Gambling Screen and sex. See Methods and Comment sections for more details. All numbers are percentages. Chisquare comparison was significant at $p<.05$.

TABLE 4. Proportions of Student-Athletes Reporting Behavior Related to Affecting Outcomes of Games, by Gender

\begin{tabular}{|c|c|c|c|}
\hline Behavior & $\begin{array}{c}\text { Men } \\
(n=12,795)\end{array}$ & $\begin{array}{c}\text { Women } \\
(n=7,734)\end{array}$ & $\begin{array}{c}\text { Overall } \\
(N=20,529)\end{array}$ \\
\hline Took money for playing poorly & 0.7 & 0.1 & 0.5 \\
\hline $\begin{array}{l}\text { Due to a sports wagering debt - asked to affect } \\
\text { outcome }\end{array}$ & 1.1 & 0.6 & 0.9 \\
\hline Due to a sports wagering debt - affected outcome & 0.5 & 0.2 & 0.4 \\
\hline
\end{tabular}

Note. Sample size of each behavior varied because of missing items and 210 respondents not indicating their gender. All numbers are percentages. Chi-square comparisons by gender were all significant at $p<.05$. 
wagering behavior among US college student-athletes. Men consistently had much higher prevalence of gambling than did their female counterparts. Depending on the type of gambling activity, the prevalence among men could be as high as almost 6 times that among women (eg, wagering on intercollegiate games with an off-campus bookie). Although researchers have found male and female differences in gambling prevalence in other study populations, our results highlight the recurring theme and underscore the importance of assessing male and female gambling behavior separately instead of simply looking at the combined prevalence, particularly in the student-athlete population. Such gender-specific information can be instrumental in identifying high-risk gambling activities and devising interventions for appropriate target groups.

Also, a gender gap persists in sports-wagering behavior among these student-athletes. In unisex sports (ie, with both male and female representations in the NCAA membership), men repeatedly reported much higher prevalence of sports wagering, ranging from 2.6 to 4.7 times the prevalence reported by women. In addition, certain sport groups (eg, athletes in golf and lacrosse) were more likely to report wagering on sporting events than were athletes in other sports. Athletes in gender-specific sports appeared to wager on sporting events more prevalently than did their same-sex counterparts in unisex sports. For example, student-athletes in male-exclusive sports in the sample (eg, ice hockey, wrestling, baseball, and football) had higher prevalence of sports wagering than did male athletes in other unisex sports, except golf and lacrosse. Likewise, female athletes in female-only sports, such as softball, field hockey, and volleyball, were also among those with relatively higher prevalence of sports wagering in female athletes.

\section{Sports Wagering and Various Gambling Activities}

We found that the prevalence estimate of sports wagering among male athletes (34.6\%) was even higher than the reported $30 \%$ among male adults (aged 18 years and older) from a recent national survey. ${ }^{16}$ Attention should also be paid to the claims of student-athletes who reported having influenced, or having been asked to influence, the outcomes of games. Although these numbers may seem small, any behavior of this sort is troubling.

Although the majority of student-athletes who gambled in the past 12 months engaged in gambling activities less than once a month, it is worth noting that $8.0 \%$ of male (985) and $1.2 \%$ of female (94) student-athletes reported playing cards or board games for money daily or at least once a week. Also, $3.0 \%$ of men (371) and $1.1 \%$ of women (82) bought lottery tickets daily or at least weekly. Further, $5.3 \%$ (657) of male student-athletes reported betting on games of personal skill, and 4.0\% (492) reported betting on sports cards daily or at least weekly.

Among the most prevalent gambling activities in studentathletes is "some other type of gambling," with $24.4 \%$ of men $(3,021)$ and $7.4 \%$ of women $(562)$ reporting engagement in such behavior in the past 12 months, and with $3.5 \%$ of men (435) reporting daily or at least weekly par- ticipation. Future qualitative research is warranted to probe and elucidate other types of gambling behavior commonly engaged in by college student-athletes.

\section{Prevalence Estimates of Problem or Pathological Gambling}

Using the DSM-IV Gambling Screen, we identified $4.3 \%$ of male and $0.4 \%$ of female college student-athletes as problem or pathological gamblers. The prevalence estimate seems comparable to the $4.2 \%$ (men) and lower than the $2.9 \%$ (women) as reported from a recent national survey among US adults. ${ }^{17}$ Although no direct figure-to-figure comparison can be made because of different research methods and measures used, our findings provide support for the notion that young men are a high-risk group for gambling problems, compared with their female counterparts.

In comparison with the meta-analytic prevalence estimates synthesized by Shaffer and Hall ${ }^{5}-5.6 \%$ as level 3 (pathological) and $10.9 \%$ as level 2 (problem) gamblers among college students-our prevalence figures seem lower. It is important, however, to note that they based their estimates on lifetime data, as was the case for the majority of the gambling literature, whereas our estimates were derived within a past-year time frame. As reported by Volberg, ${ }^{18}$ lifetime rates of pathological gambling are routinely 2 to 3 times higher than are the current (past-year) rates. Another critical difference is that we used the DSM$I V$ criteria, whereas Shaffer and Hall ${ }^{5}$ based their estimates primarily on the most commonly used instrument, the South Oaks Gambling Screen (SOGS), ${ }^{19}$ which has been criticized by some for having the tendency to overestimate. ${ }^{20}$ Last but not least, Shaffer and $\mathrm{Hall}^{5}$ did not separate their prevalence estimates by gender, and given the well-known male and female difference in gambling prevalence, their estimates could be biased in either direction, depending on the gender distributions of their study samples.

\section{College Student-Athletes vs Nonathletes}

Data collection from a national sample of nonathlete college students is beyond the scope of our study. It is informative, however, to compare our results with those from recent gambling studies conducted in the general college student population. ${ }^{9,12}$ Although different measures of pathologi$\mathrm{cal} /$ problem gambling were used, thereby precluding direct comparisons in the prevalence figures of gambling problems, we can examine other measures of gambling to get a snapshot of the extent of gambling involvement among student-athletes versus nonathletes.

For example, we made the following comparisons on the basis of the findings from the 2001 Harvard School of Public Health College Alcohol Study (CAS), which was also the first national survey of gambling among the general US college student population. ${ }^{9}$ Approximately $52 \%$ of men and $33 \%$ of women reported that they gambled during the past school year, compared with $62.4 \%$ and $42.8 \%$ in the past year, respectively, among our NCAA student-athletes. The most popular type of gambling in the CAS sample 
was playing the lottery, with $24.7 \%$ of students overall reporting participation in that activity and $1.2 \%$ reporting that they participated in it at least weekly. Note that CAS did not report gambling prevalence separately by gender. In contrast, although lottery was not the most common gambling activity in our NCAA sample, the overall pastyear prevalence was $33.0 \%$ (35.7\% in men and $28.5 \%$ in women), exceeding that of CAS. Further, as for daily or at least weekly participation in lottery, the overall prevalence was $2.3 \%$ (3.0\% in men and $1.1 \%$ in women) in our NCAA sample. Also, for other popular gambling activities, such as playing cards, shooting dice, or playing other games of chance, student-athletes all appeared to have higher rates of participation compared with other students. Although the above evidence seems to suggest that college studentathletes could gamble more commonly and frequently than do their nonathlete peers, researchers need to address such comparisons more directly in future studies.

Similar to prior research on gambling motives among college students, we also found that the most commonly cited reasons for student-athletes to gamble were "for fun," followed by "to win money" and "for excitement," with nearly $50 \%$ more athletes endorsing "for fun" than "to win money." However, in a study by Neighbors et $\mathrm{al}^{21}$ among the general college student population, they found that winning money was the top motive for gambling, nearly double the rate of endorsement for fun/enjoyment as the primary motive for gambling. This suggests that although there is commonality in the primary reasons for gambling, there could be distinct differences in the relative importance of these reasons between the general college student and the student-athlete populations. More research is needed to examine such motivational differences so as to provide critical information for the development of effective gambling intervention programs for different segments of the college student population.

\section{Methodological Caveats}

An important methodological issue that merits discussion is that we found inconsistencies between self-reported gambling behavior and self-perceived gambling problems. For example, 177 respondents reported no gambling activity in the past 12 months, but they still reported experiencing gambling-related problems on the DSM scale. This phenomenon is reminiscent of recovering alcoholics in alcohol research, in which former problem drinkers, although currently abstinent, still struggle with some alcohol-related issues. Because of such problem-drinking history, they cannot be regarded as the same as other abstainers without such history. ${ }^{22}$ Following the same line of argument, one might speculate that these were recovering pathological gamblers. Therefore, we did not classify them as nongamblers nor did we include them in any DSM-based analyses as gamblers. Researchers could explore this particular group further because people with an alleged problem-gambling history, could have different risk profiles, attitudinal characteristics, or behavioral correlates that would separate them from current nongamblers without a problem-gambling history.
Equally noteworthy is that 3,275 respondents (16\% of the sample) reported participation in gambling activities during the past 12 months but skipped the DSM Gambling Screen questions entirely as if they were nongamblers. (Note that we instructed respondents to skip this section if they "have not gambled, bet, or wagered in any way during the past 12 months.") Because of the lack of DSM information, we did not include these respondents in the gambling prevalence analysis that was based on the DSM score. It is possible that these respondents were gamblers with problems who were in denial and who refused to answer the questions related to their gambling problems. It is also likely that these respondents might not regard their gambling behavior as gambling. This finding highlights the importance of verifying the respondent's self-identified gambling status with some actual behavioral questions, such as participation in various gambling activities as illustrated in our study. This has significant research implications because the classification of a respondent's gambling versus nongambling status would affect the estimate of population prevalence of gambling.

\section{Limitations}

Besides the aforementioned methodological caveats we uncovered, there are inherent limitations. First, because we designed the study methods to guarantee responding student-athletes' anonymity, the NCAA was not able to track the responses on a school-by-school or team-by-team basis. Therefore, we could not calculate an exact response rate. Further, even with the measures implemented in the survey administration process to ensure anonymity, it is still reasonable to suspect that self-reported levels of gambling, sports wagering, and associated behaviors might be underestimated because of the sensitive nature of the questions asked, especially with athletic and scholarship eligibility at stake.

\section{Conclusions}

To our knowledge, this study represents the first national survey of gambling among US college student-athletes. The recurring male and female differences found in this study highlight the importance of estimating and reporting gambling prevalence figures separately by gender for more accurate cross-study comparisons. Another gender-related issue for future research is why athletes in gender-specific sports indicated more sports wagering than did those in unisex sports. Qualitative research is also warranted in which investigators should elucidate the other types of gambling commonly engaged in by college athletes, as well as examine the motivational differences in gambling between student-athletes and nonathletes. Experts should also pay attention to methodological issues concerning verification of respondents' gambling status in estimating population prevalence figures.

In conclusion, although the prevalence of gambling problems could be underestimated in this population as discussed previously, this study has provided a national baseline set of data against which the gambling and sports wagering behavior of future cohorts of NCAA student-athletes can be measured. As targeted education programs and other inter- 
ventions are developed, it will be crucial to conduct periodic checks of the progress being made in reducing the prevalence of gambling problems among college student-athletes.

\section{ACKNOWLEDGMENT}

The NCAA provided financial support for this study. The authors thank Todd Petr, the research coordinator at NCAA, as well as the more than 20,000 student-athletes for their close attention and candor in responding to the extensive questionnaire, representing NCAA's first national study on collegiate sports wagering and associated health-risk behaviors.

\section{NOTE}

For comments and further information, address correspondence to Dr Jiun-Hau Huang, McGill University, Educational \& Counselling Psychology, 3724 McTavish Street, Montreal, Quebec, H3A 1Y2, Canada (e-mail: jiun-hau. huang@mcgill.ca).

\section{REFERENCES}

1.Derevensky JL, Gupta R. Prevalence estimates of adolescent gambling: a comparison of the SOGS-RA, DSM-IV-J, and the GA 20 questions. J Gambl Stud. 2000;16:227-251.

2.Derevensky JL, Gupta R, Winters K. Prevalence rates of youth gambling problems: are the current rates inflated? J Gambl Stud. 2003;19:405-425.

3. Shaffer HJ, Hall MN. Estimating the prevalence of adolescent gambling disorders: a quantitative synthesis and guide toward standard gambling nomenclature. J Gambl Stud. 1996;12:193-214.

4. Shaffer HJ, Hall MN, Vander Bilt J. Estimating the prevalence of disordered gambling behavior in the United States and Canada: a research synthesis. Am J Public Health. 1999;89:1369-1376.

5. Shaffer HJ, Hall MN. Updating and refining prevalence estimates of disordered gambling behaviour in the United States and Canada. Can J Public Health. 2001;92:168-172.

6.Jacobs DF. Juvenile gambling in North America: an analysis of long-term trends and future prospects. J Gambl Stud. 2000;16:119-152.

7. Messerlian C, Derevensky J, Gupta R. Youth gambling problems: a public health perspective. Health Promot Int. 2005;20:69-79.
8. Kaminer V, Petry NM. Gambling behavior in youths: why we should be concerned. Psychiatr Serv. 1999;50:167-168.

9.LaBrie RA, Shaffer HJ, LaPlante DA, Wechsler H. Correlates of college student gambling in the United States. J Am Coll Health. 2003;52:53-62.

10. Winters KC, Bengston P, Dorr D, Stinchfield R. Prevalence and risk factors of problem gambling among college students. Psychol Addict Behav. 1998;12:127-135.

11.Lesieur HR, Cross J, Frank M, et al. Gambling and pathological gambling among university students. Addict Behav. 1991;16:517-527.

12.Engwall D, Hunter R, Steinberg M. Gambling and other risk behaviors on university campuses. $J$ Am Coll Health. 2004;52:245-255.

13. Cullen FT, Latessa EJ. The Extent and Sources of NCAA Rule Infractions: A National Self-Report Study of Student-Athletes. Kansas City, MO: National Collegiate Athletic Association; 1996.

14. Cross ME, Vollano AG. The Extent and Nature of Gambling Among College Student-Athletes. Ann Arbor, MI: University of Michigan Department of Athletics; 1999.

15. American Psychiatric Association. Diagnostic and Statistical Manual of Mental Disorders. 4th ed. Washington, DC: American Psychiatric Association; 1994.

16. National Collegiate Athletic Association. NCAA National Study on Collegiate Sports Wagering and Associated HealthRisk Behaviors. Indianapolis, IN: The National Collegiate Athletic Association; 2003.

17. Welte JW, Barnes GM, Wieczorek WF, Tidwell MC, Parker J. Gambling participation in the US-results from a national survey. J Gambl Stud. 2002;18:313-337.

18. Volberg RA. Prevalence studies of problem gambling in the United States. J Gambl Stud. 1996;12:111-128.

19.Lesieur HR, Blume SB. The South Oaks Gambling Screen (SOGS): a new instrument for the identification of pathological gamblers. Am J Psychiatry. 1987;144:1184-1188.

20.Derevensky JL, Gupta R. Measuring gambling problems amongst adolescents: current status and future directions. Int Gambl Stud. 2006;6:201-215.

21. Neighbors C, Lostutter TW, Cronce JM, Larimer ME. Exploring college student gambling motivation. J Gambl Stud. 2002;18:361-370.

22.Huang JH, Dejong W, Kessel Schneider S, Gomberg Towvim L. Measuring college student drinking: illustrating the feasibility of a composite drinking scale. Subst Abus. 2006;27:33-45.

\section{APPENDIX \\ DSM-IV Gambling Screen: 10 Questions With Yes/No Answers (Past 12 Months)}
1. Have there been periods in the past year where you spent a lot of time thinking about past gambling experiences, thinking about future gambling experiences, or thinking about ways of getting money with which to gamble?
2. During the past year, have you needed to gamble with larger amounts of money or with larger bets in order to obtain the same feeling of excitement?
3. Have you tried to cut down or stop your gambling several times in the past year and been unsuccessful?
4. Did you feel quite restless or irritable after you tried to cut down or stop gambling?
5. Do you feel that you gamble as a way to run away from personal problems or to relieve uncomfortable emotions such as nervousness or sadness?
6. After you lose money gambling, do you often return another day to try to win back your losses?
7. Have you lied to family members, friends, or others in order to hide your gambling?
8. Have you committed any illegal acts (such as theft, forgery, embezzlement, or fraud) to finance your gambling?
9. Have you almost lost, or actually lost, a relationship with someone important to you, or a job, school, or career opportunity because of your gambling?
10. Have you relied on others to bail you out and pay our gambling debts or to pay your bills when you have financial problems because of gambling?

Note. DSM-IV = Diagnostic and Statistical Manual of Mental Disorders, 4 th ed. ${ }^{15}$ 


\section{$(A)(C)(A)|\mathbf{W}| \mathbf{H} \mid \mathbf{A}$}

American College Health Association National College Health Assessment

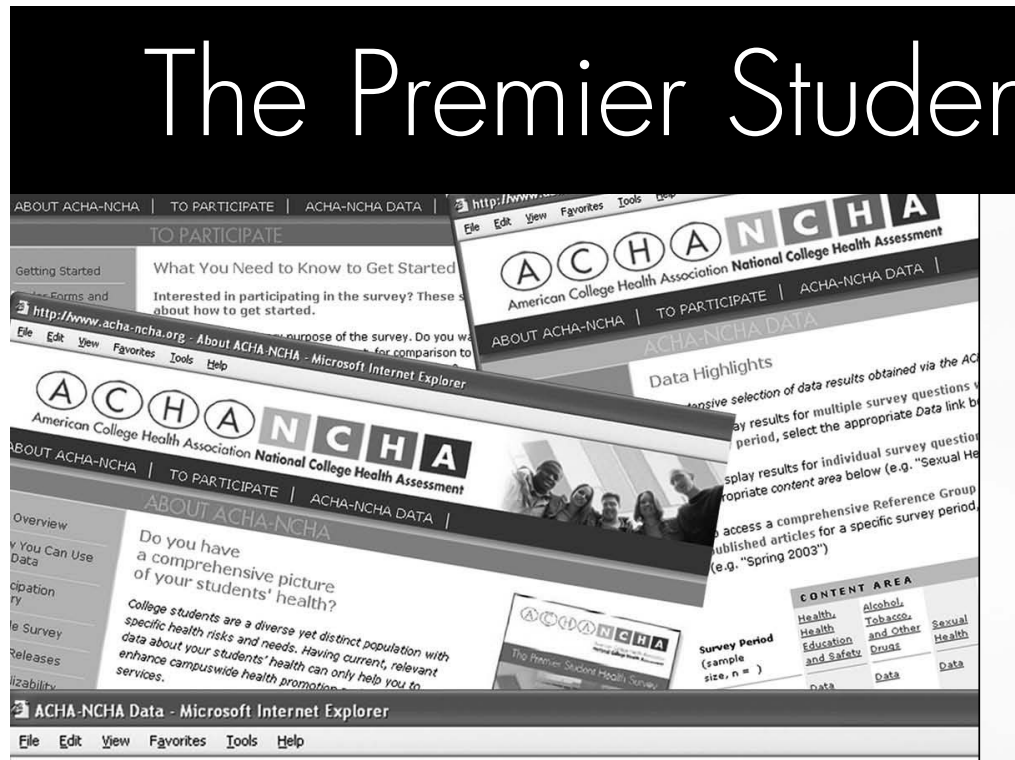

(A) (C) (A) A N C IHA

American College Health Association National College Health Assessment

\section{ABOUT ACHA-NCHA | TO PARTICIPATE | ACHA-NCHA DATA |}

The Premier Student Health Survey

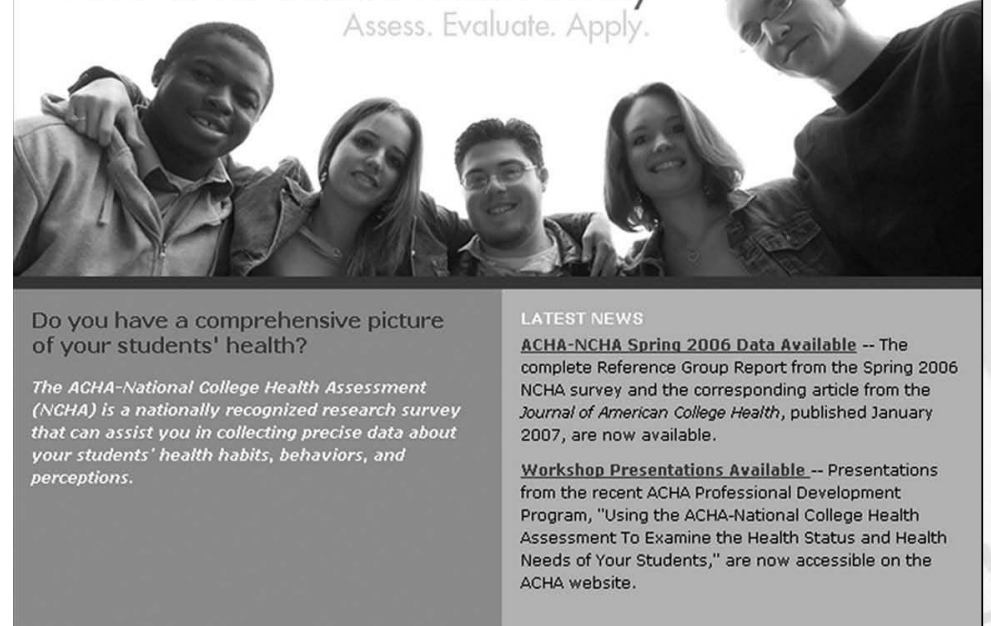

Having current, relevant data about your students' health can only help you to enhance campuswide health promotion and prevention services.

The American College Health Association's National College Health Assessment (ACHA-NCHA) - a nationally recognized research survey - can assist you in collecting precise data about your students' habits, behaviors, and perceptions on the widest range of health issues:

- Alcohol, tobacco, and other drug use

- Sexual health

- Weight, nutrition, and exercise

- Mental health

- Personal safety and violence

T. American College Health Association

Fall 2006 Data Report and Executive Summary now available at www.acha-ncha.org! Visit our website for detailed information about the survey and how to participate. Or, call the ACHA-NCHA Program Office at (410) 859-1500. 